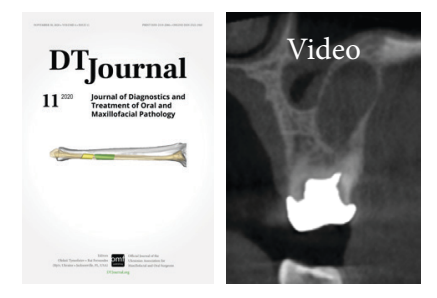

\title{
SERIES
}

\section{Single and Multiple Odontogenic Cutaneous Sinus Tracts}

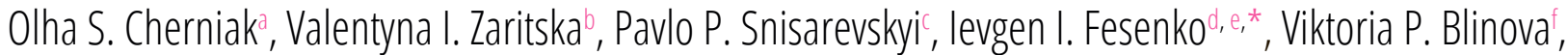 \\ Nataliia M. Kobå, Ruslan A. Pavlenkoh, \& Viktoria M. Holodenko
}

\section{SUMMARY}

Odontogenic cutaneous sinus tract (OCST) (synonyms: odontogenic cutaneous fistula, odontogenic subcutaneous granuloma, etc.) is an abnormal tube-shape formation which serves as a pathway for pus drainage from the locus of tooth-associated infection to the cutaneous lesion. OCST is a collective term and commonly is manifested in six cutaneous forms: as dimpling with fistula, cutaneous infiltration, nodule, suppurated nodule, abscess, or even cyst-like cutaneous formation. The purpose of this paper is to present the diverse clinical and radiological appearance (cone-beam computed tomography [CBCT] and ultrasound [US]) of single and multiple OCSTs based on the literature and our four cases. As long as limited publications present the ultrasound appearance of the OCSTs, we will focus on meticulous description of sonograms as well, giving a possibility for oral and maxillofacial surgeons to understand all advantages of that type of non-ionizing radiation diagnostics, avoiding misdiagnosis and mistreatment of OCSTs.

Case 1: A 24-year-old male with OCST to the left mandibular region from the lower left first molar. Cutaneous lesion of OCST manifested as a transition stage from cutaneous infiltration to abscess.

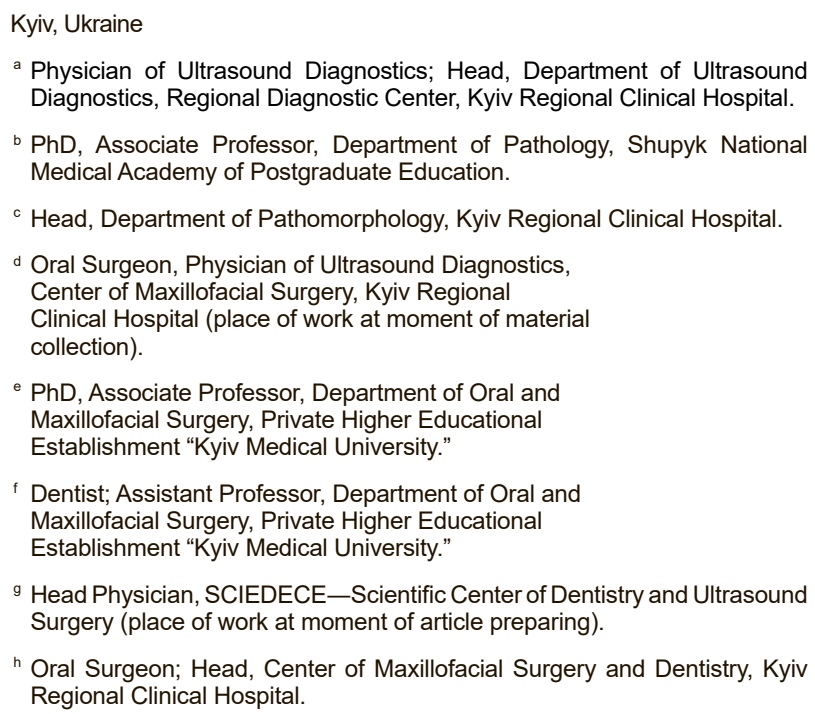

a Physician of Ultrasound Diagnostics; Head, Department of Ultrasound Diagnostics, Regional Diagnostic Center, Kyiv Regional Clinical Hospital.

${ }^{b} \mathrm{PhD}$, Associate Professor, Department of Pathology, Shupyk National Medical Academy of Postgraduate Education.

${ }^{c}$ Head, Department of Pathomorphology, Kyiv Regional Clinical Hospital.

d Oral Surgeon, Physician of Ultrasound Diagnostics, Center of Maxillofacial Surgery, Kyiv Regional Clinical Hospital (place of work at moment of material collection).

e PhD, Associate Professor, Department of Oral and Maxillofacial Surgery, Private Higher Educational Establishment "Kyiv Medical University."

${ }^{f}$ Dentist; Assistant Professor, Department of Oral and Maxillofacial Surgery, Private Higher Educational Establishment "Kyiv Medical University."

${ }^{g}$ Head Physician, SCIEDECE-Scientific Center of Dentistry and Ultrasound Surgery (place of work at moment of article preparing).

${ }^{\text {n }}$ Oral Surgeon; Head, Center of Maxillofacial Surgery and Dentistry, Kyiv Regional Clinical Hospital.

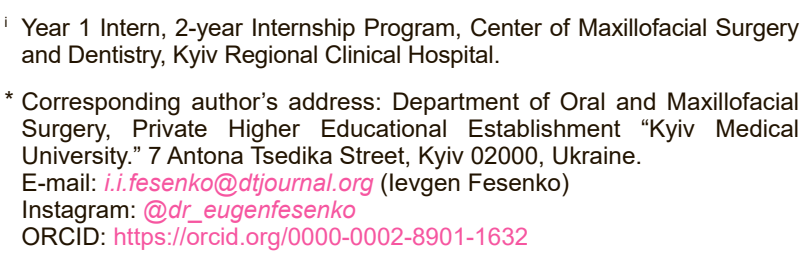

Year 1 Intern, 2-year Internship Program, Center of Maxillofacial Surgery and Dentistry, Kyiv Regional Clinical Hospital.

* Corresponding author's address: Department of Oral and Maxillofacial Surgery, Private Higher Educational Establishment "Kyiv Medical University." 7 Antona Tsedika Street, Kyiv 02000, Ukraine. E-mail: i.i.fesenko@dtjournal.org (levgen Fesenko) Instagram: @dr_eugenfesenko ORCID: https://orcid.org/0000-0002-8901-1632

Please cite this article as: Cherniak OS, Zaritska VI, Snisarevskyi PP, Fesenko II, Blinova VP, Koba NM, Pavlenko RA, Holodenko VM. Single and multiple odontogenic cutaneous sinus tracts. J Diagn Treat Oral Maxillofac Pathol 2020;4(11):197-216.

The word 'Video' at the upper right icon means that article contains cases with video.

Paper received 25 October 2020

Accepted 15 November 2020

Available online 30 November 2020

https://dx.doi.org/10.23999/j.dtomp.2020.11.2.

(C) 2020 OMF Publishing, LLC. This is an open access article under the CC BY license (http://creativecommons.org/licenses/by-nc/4.0/). 
Case 2: A 41-year-old male with odontogenic cutaneous fistula of the right mandibular body region from the lower right second molar. It's manifested as deep dimpling with active fistula.

Case 3: A 45-year-old male with unilateral multiple OCSTs: 1) odontogenic cutaneous fistula of the left cheek from the left second maxillary molar and 2) a scar from a surgically treated OCST located in the projection of the left mandible from the tooth \#3.6.

Case 4: An 18-year-old male with OCST to left nasolabial fold and cheek from the upper left first molar. The pathology manifested as a subcutaneous abscess first and a nodule after the abscess lancing.

These cases highlight the diverse cutaneous manifestations of the OCSTs. The US appearances of different parts of the OCST are presented, the popular terminology for the same cutaneous lesions are discussed, the new terms are proposed, and the treatment strategies based on histologic results are debated.

\section{INTRODUCTION}

Odont dontogenic cutaneous sinus tract ${ }^{1}$ (synonyms: odontogenic cutaneous fistula, ${ }^{2,3}$ extraoral sinus tract of endodontic origin ${ }^{4}$, odontogenic subcutaneous granuloma ${ }^{5}$, etc.) is an abnormal tube-shape formation which serves as a pathway for pus drainage from the locus of tooth-associated infection to the cutaneous lesion.

Odontogenic cutaneous sinus tract (OCST) is a collective term and commonly is manifested in six cutaneous forms: as dimpling with fistula, cutaneous infiltration, nodule, suppurated nodule, abscess, or even cyst-like cutaneous formation. ${ }^{3}$ Other common name for the cutaneous infiltration/abscess appearance is odontogenic subcutaneous granuloma. ${ }^{5}$ Those two clinically different manifestations are two clinical stages and in some countries are jointly named as odontogenic subcutaneous granuloma which has two clinical forms. Moreover, in some cases, when a subcutaneous granuloma do not has the sinus tract and the focus of odontogenic infection, it is considered non-odontogenic. ${ }^{6}$ In particular, Tymofieiev observed the onset of non-odontogenic subcutaneous granuloma due to the penetration of such organic-composed foreign bodies ${ }^{6}$ as a pine needle and nail.

Some cutaneous manifestations of the OCST the authors describe as ulcerated nodules ${ }^{7}$ and nodulocystic cutaneous lesions $\mathrm{s}^{7,8}$.

One of the previously applied names for the OCST with fistula and notable extraoral pyorrhea was a "Partsch chronic granulating periodontitis".

The purpose of this paper is to present the diverse clinical and radiological appearance (cone-beam computed tomography [CBCT] and ultrasound [US]) of a single and multiple OCSTs based on the literature and our four cases. Limited publications ${ }^{7,10,1,4}$ exist presenting ultrasonographic appearance of the OCSTs, so we will focus on meticulous description of sonograms as well, giving a possibility for oral and maxillofacial surgeons to understand all advantages of that type of non-ionizing radiation diagnostics, avoiding misdiagnosis and mistreatment of OCSTs.

\section{REPORT OF CASES}

\section{CASE 1}

In February 2012, a 24-year-old male was referred to the Center of Maxillofacial Surgery with complaints for several-week redness in the left mandibular region (Fig 1). Extraoral examination showed a round shape skin erythema with cutaneous infiltration. Intraoral examination revealed a destroyed crown of the tooth \#3.6 by carious process. Panoramic radiography showed periapical radiolucency at the roots of mandibular first left molar measured $8.6 \times 9$ $\mathrm{mm}$ with no filling material inside the canals. Palpation revealed a firm strand from alveolar bone to the left mandibular region passing into the submucosal layer. Clinically, the cutaneous lesion manifested as a transition stage from infiltration to abscess stage of odontogenic subcutaneous granuloma. Cutaneous manifestations completely self-disappeared (after tooth \#3.6 removal and prescription of antibiotics) at 25-day follow-up. Such fact gave us a reason to hypothesize that the case was a reversible cutaneous manifestation of OCST with no need of surgery. 

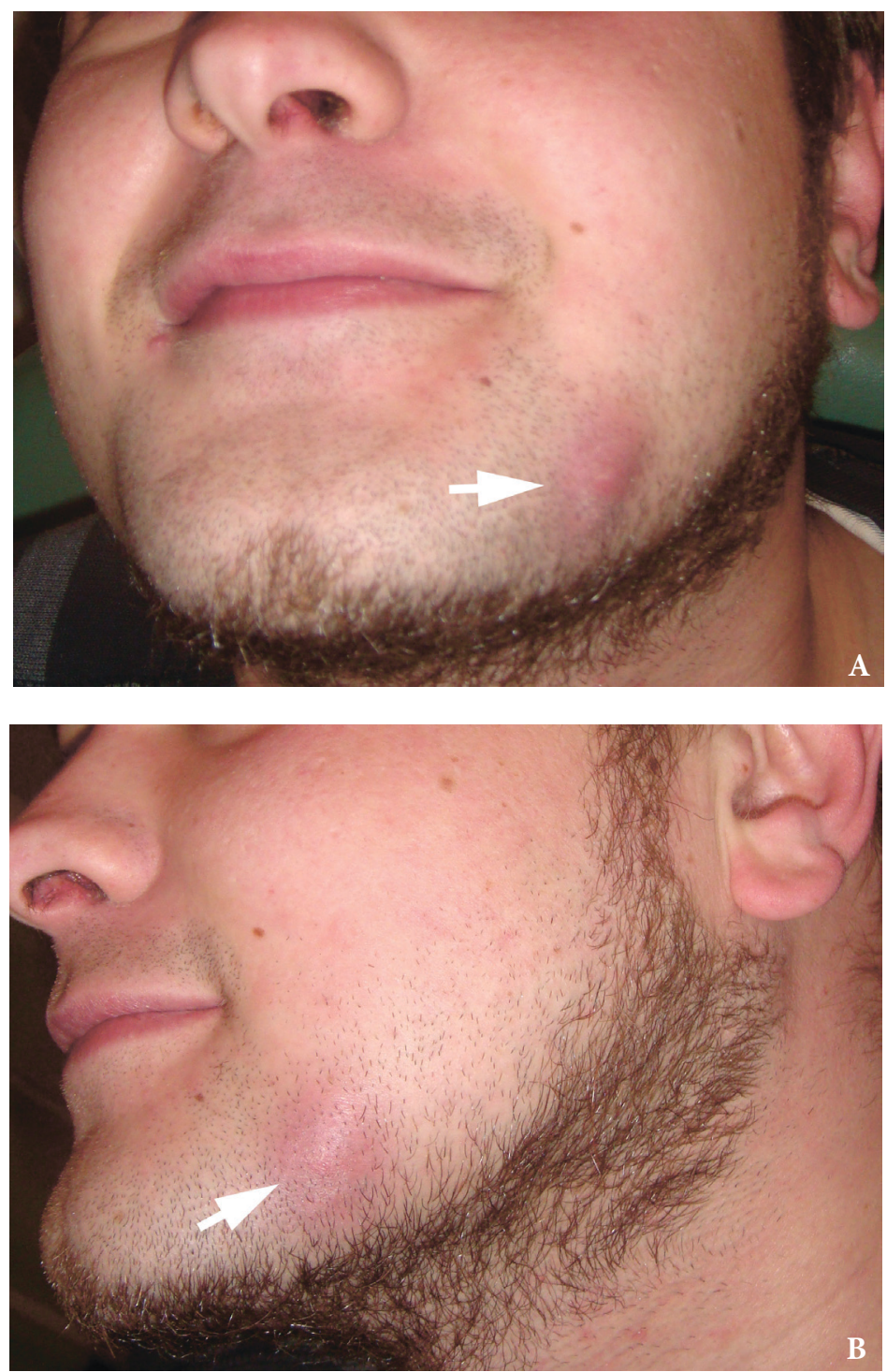

FIGURE 1. Case 1: A 24-year-old male with odontogenic cutaneous sinus tract $(\mathbf{A}, \mathbf{B})$ to the left mandibular region from the lower left first molar. OCST manifested as a transition stage from cutaneous infiltration to abscess of odontogenic subcutaneous granuloma (arrow). Cutaneous manifestations completely self-disappeared (after tooth \#3.6 removal and prescription of antibiotic) at 25-day follow-up. Printed with permission and copyrights retained by R.A.P.

\section{CASE 2}

In January 2015, a 41-year-old male was referred to the Center of Maxillofacial Surgery and Dentistry with cosmetic complaints - a deep skin dimpling with active fistula in the right mandibular area (Fig $2 \mathrm{~A}$ and $\mathrm{B})$. Periodically, during the last years, the patient noted the appearance of purulent discharge in the center of dimpling.

Intraorally, a firm strand was palpated from the alveolar bone of the lower right second molar to the cutaneous fistula. Simultaneously, a horizontal oblique anteroposterior direction of the strand was noted. No visual mucosal changes were vizualized (Fig 2C).

Cone-beam computed tomography (CBCT) (Planmeca ProMax 3D, Helsinki, Finland) showed the absence of contrast filling material in all three canals of the tooth \#4.7 and well-defined periradicular radiolucency around roots' ends and in a furcation area with an oval shape buccal cortical plate defect (Fig 2D-G). Using of a "draw 
a panoramic curve" tool in the Planmeca Romexis Viewer 3.8.3R 15.12.14 allowed obtaining a panoramic view (Fig 2G).

Removal of the sinus tract and extraction of a tooth \#4.7 have been performed under general anesthesia with local vestibular infiltration by $1.4 \mathrm{ml}$ Ultracain D-S Forte (4 percent articaine hydrochloride, Aventis Pharma Deutschland $\mathrm{GmbH}$, Frankfurt am Main, Germany). First, the elevation of the mucoperiosteal flap with dissection of the sinus tract originated from the tooth \#4.7`s alveola was done (Fig 2H). Then, the tract and a cutaneous fistula have been excised (Fig 2I and J) with a local plastic closure of the skin defect.

Histopathological examination of the specimen (ie, sinus tract) established the presence of the soft tissues with a cavity lined with granulations and inflammation around.

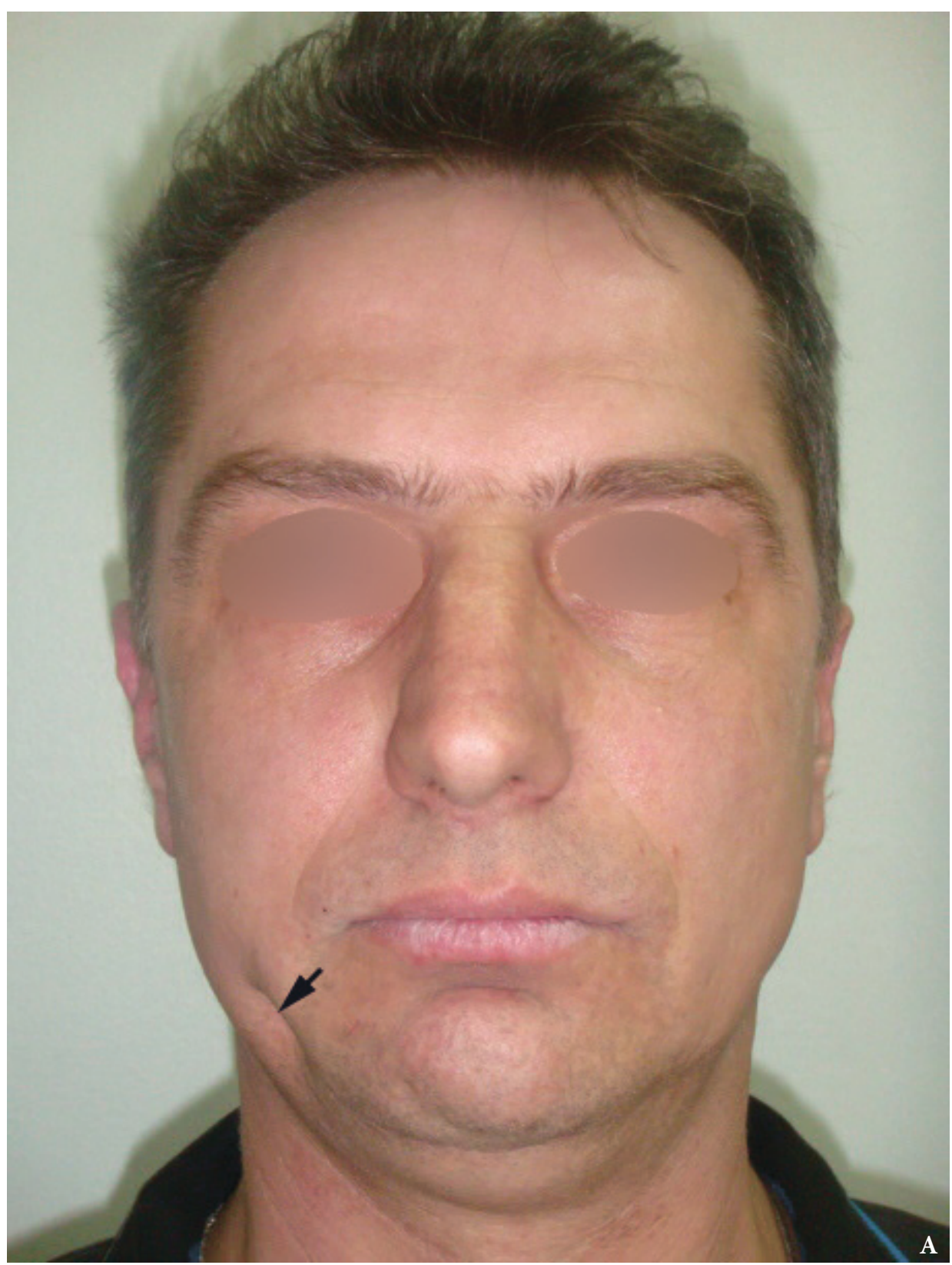

FIGURE 2. Case 2: A 41-year-old male with odontogenic cutaneous fistula of the right mandibular body region from the lower right second molar (ie, tooth \#4.7). At the anterior view $(\mathbf{A})$ the deep skin dimpling is indicated by arrow. Printed with permission and copyrights retained by l.I.F. (Fig 2 continued on next page.) 

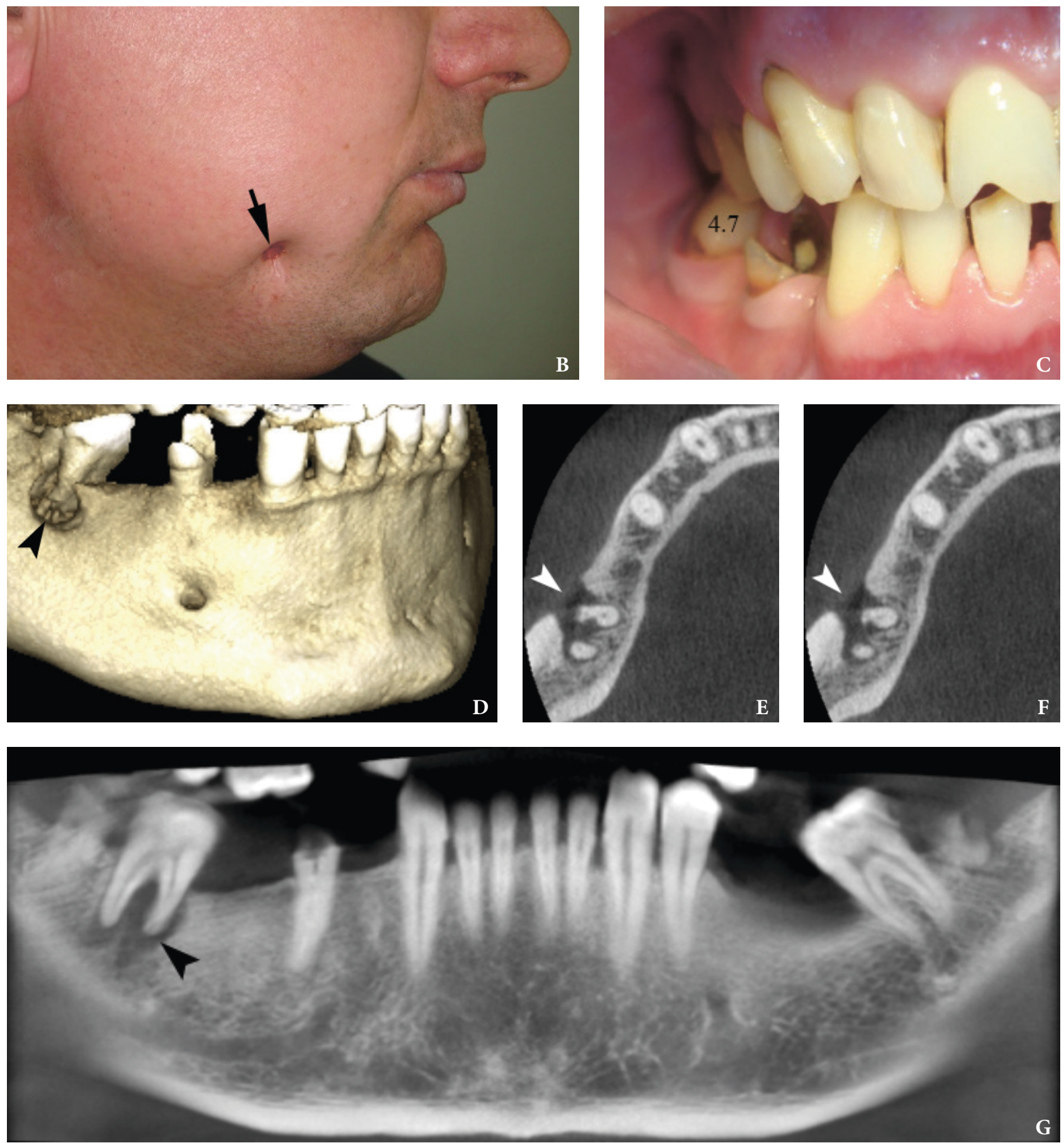

FIGURE 2 (continued). Case 2: A 41-year-old male with odontogenic cutaneous fistula of the right mandibular body region from the lower right second molar (ie, tooth \#4.7). At the lateral view (B) the deep skin dimpling is indicated by arrow. $\mathbf{C}$ - No visual mucosal changes were noted near the teeth \#4.7 and 4.5. Three-dimensional CBCT (D) visualized an oval shape defect (arrowhead) on the buccal cortical plate. Axial scans (E, F) and panoramic view $(\mathbf{G})$ (obtained using a tool "draw a panoramic curve") showed well-defined periradicular radiolucency with buccal defect (arrowheads) around the tooth \#4.7 and no contrast filling material in its all three canals (mesiobuccal, mesiolingual, and distal). Printed with permission and copyrights retained by I.I.F. (Fig 2 continued on next page.) 

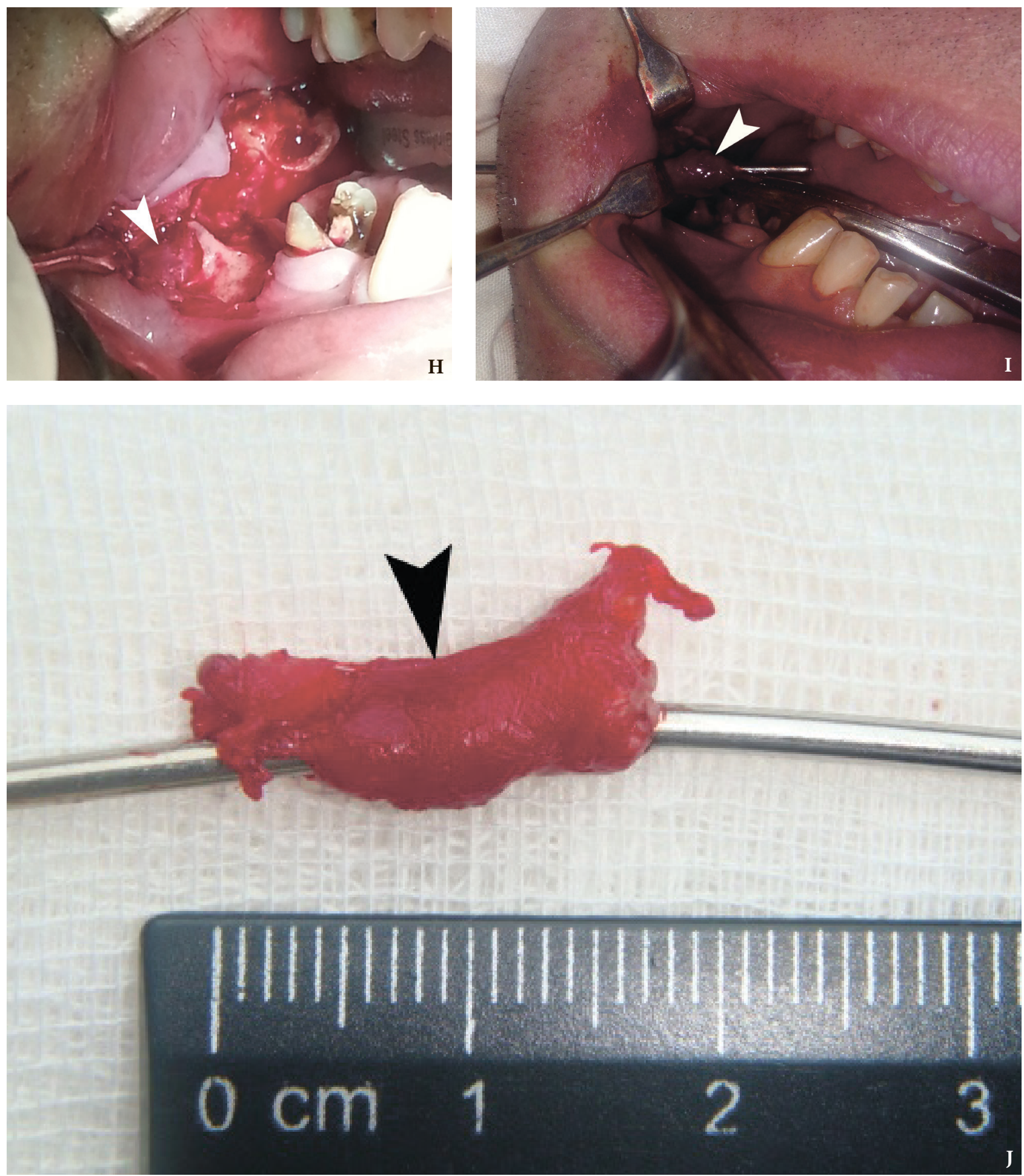

FIGURE 2 (continued). Case 2: A 41-year-old male with odontogenic cutaneous fistula of the right mandibular body region from the lower right second molar (ie, tooth \#4.7). Image $\mathbf{H}$ demonstrates operative field after elevation of the mucoperiosteal flap and dissection of the sinus tract (arrowhead) originated from the tooth \#4.7 alveola through the buccal plate perforation. On the images during ( $\mathbf{I}$ ) and after $\mathbf{J})$ the excision the sinus tract is labeled by arrowhead. Total length of the tract reached $1.3 \mathrm{~cm}$. Printed with permission and copyrights retained by I.I.F. 


\section{CASE 3}

In March 2016, a 45-year-old male was treated in Orthopedic Surgery Department due to the fracture of lower extremity. Simultaneously, an odontogenic cutaneous fistula of the left cheek (Fig 3) from the maxillary left second molar was diagnosed by an oral surgeon of the same hospital. Despite the recommendations the patient declined the further maxillofacial diagnostics and treatment. Figure 3 also demonstrates a scar in the left mandibular region where a similar fistula had been excised several years ago (according to patient's words). During surgery, a causative tooth \#3.6 was extracted. So, that case with unilateral multiple OCSTs supports the data of Tymofieiev describing multiple odontogenic cutaneous sinus tracts with cutaneous manifestations in a form of infiltration or abscess. ${ }^{5,6}$

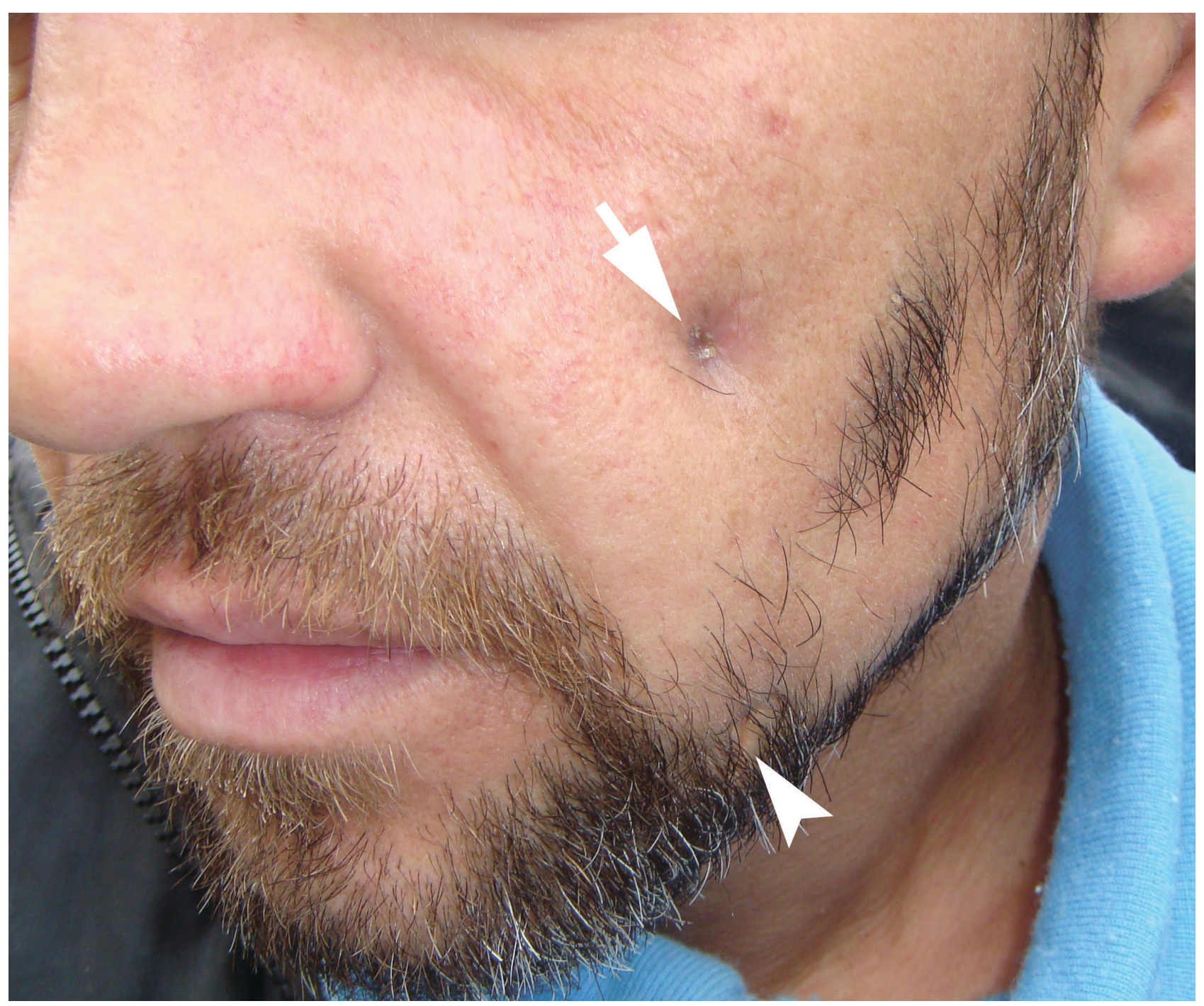

FIGURE 3. Case 3: A 45-year-old male with odontogenic cutaneous fistula (arrow) of the left cheek from the maxillary left second molar. Arrowhead labels a postoperative scar in the left mandibular region where a similar fistula had been excised several years ago in other hospital. Printed with permission and copyrights retained by I.I.F. 


\section{CASE 4}

In July 2016, an 18-year-old male was referred to the Center of Maxillofacial Surgery and Dentistry complaining for a painful increasing skin swelling in the left cheek region with erythema. According to patient's words, edema started to grow after the football game left cheek trauma.

During the extraoral examination, an oval shape painful skin erythema with well-defined margins (Fig 4A and B) was noted in the region of left nasolabial fold and upper aspect of buccal region. Intraoral examination with palpation revealed a firm strand (synonym: cord-like ${ }^{8}$ formation) in submucosal layer originated from the buccal alveolar bone near tooth \#2.6 passing to the region of left nasolabial fold. Tooth \#2.6 was non-movable and percussion test was negative. Figures $4 \mathrm{C}$ and $\mathrm{D}$ have been taken 19 days after the abscess was surgically drained: an oval-shaped erythematous nodule in a place of the previously treated subcutaneous abscess was visualized.

CBCT (Planmeca ProMax 3D, Helsinki, Finland), performed during the first visit (Figs $4 \mathrm{E}-\mathrm{M})$, showed two incompletely treated canals of the tooth \#2.6: mesiobuccal - with round shape periapical radiolucency measured $0.91 \times 0.7 \times$ $1.36 \mathrm{~cm}$ involving buccal plate and palatal - with periapical radiolucency measured $0.58 \times 0.46 \times 0.64$ $\mathrm{cm}$. According to the CT, palatal canal was sealed $3 / 4$ of the length and mesiobuccal $-1 / 4$ of the length.

A minimal $(1.72 \mathrm{~mm})$ maxillary sinus mucosa thickening ${ }^{11}$ (Fig 4M) was observed at the inferior and lateral walls of the left antrum (ie, left maxillary sinus) close to the periapical radiolucency areas. According to Bornstein et al, ${ }^{12}$ mucosal thickening less than $2 \mathrm{~mm}$ is considered as a non-pathologic sinus membrane.

Figure $4 \mathrm{~N}$ demonstrates the longitudinal position (related to sinus tract passage) of the linear probe (frequency range: 12-3 MHz) during ultrasonography (model HD11 XE, Philips) on day 19 after the subcutaneous abscess lancing with antibiotic prescription. Gray scale ultrasound (Fig 4O) showed hypoechoic triangular well-defined lesion (measured $1.11 \mathrm{~cm}$ in longitudinal direction) in subcutaneous layer with a tube-form hypoechoic curved continuation $(0.62 \mathrm{~cm}$ in diameter and $2.19 \mathrm{~cm}$ in length) to the echoic surface of the left maxilla. Artifact of acoustic shadowing was clearly visualized behind the echoic surface. Thelack of intralesional vascularity on color (Fig 4 P) and power (Fig 4Q) Doppler sonograms indicated the team that there was no acute inflammation in the area of lesion. US of the intraosseous part (ie, tooth \#2.6 periradicular lesion 's part) of the tract (Fig 4R) showed a round-shaped hypoechoic lesion (with heterogenic content) measured $0.7 \times 1.02 \mathrm{~cm}$ and surrounded by echoic borders of intraosseous maxillary cavity (formed by chronic periapical abscess).

The surgery was done under general anesthesia with local infiltration by $1.4 \mathrm{ml}$ Ultracain D-S Forte (4 percent articaine hydrochloride, Aventis Pharma Deutschland GmbH, Frankfurt am Main, Germany). First, the mucoperiosteal flap was reflected and a cordlike sinus tract was dissected (Fig 4S) after its empty structure and direction has been confirmed through the transnodal (ie, transcutaneous) introduction of a metal probe. Then, simultaneously with cutaneous nodule, the tract was excised and the tooth $\# 2.6$ was extracted.

Histologic examination of the specimen revealed granulomatous tissue with inflammation.

Video 1 showes periradicular lesion of the tooth \#2.6 which involved both apices and furcation area.

Video is available in the page of the full-text article on dtjournal.org and in the YouTube channel, available at https://youtu.be/QkQDvrRMZYw. Total video`s duration: 39 seconds.

\section{RESULTS}

Analysis of the four cases with OCSTs revealed (Table 1):

1. A completeresolution of cutaneous manifestation (after causative tooth extraction and antibiotics prescription) in a 24-year-old male with OCST to the left mandibular region from the lower left first molar. His cutaneous lesion of OCST manifested as a cutaneous infiltration stage.

2. A case with 45-year-old male with unilateral multiple OCSTs confirmed the literature data about the multiple OCSTs from different teeth.

3. Histologic report in two cases with OCST (one manifested as cutaneous dimpling with stoma [ie, fistula] and second as cutaneous nodule), managed with tooth extraction, sinus tract and cutaneous excision, showed that in both cases the presence of the soft tissues with a cavity lined with granulations and inflammation around were noted. 

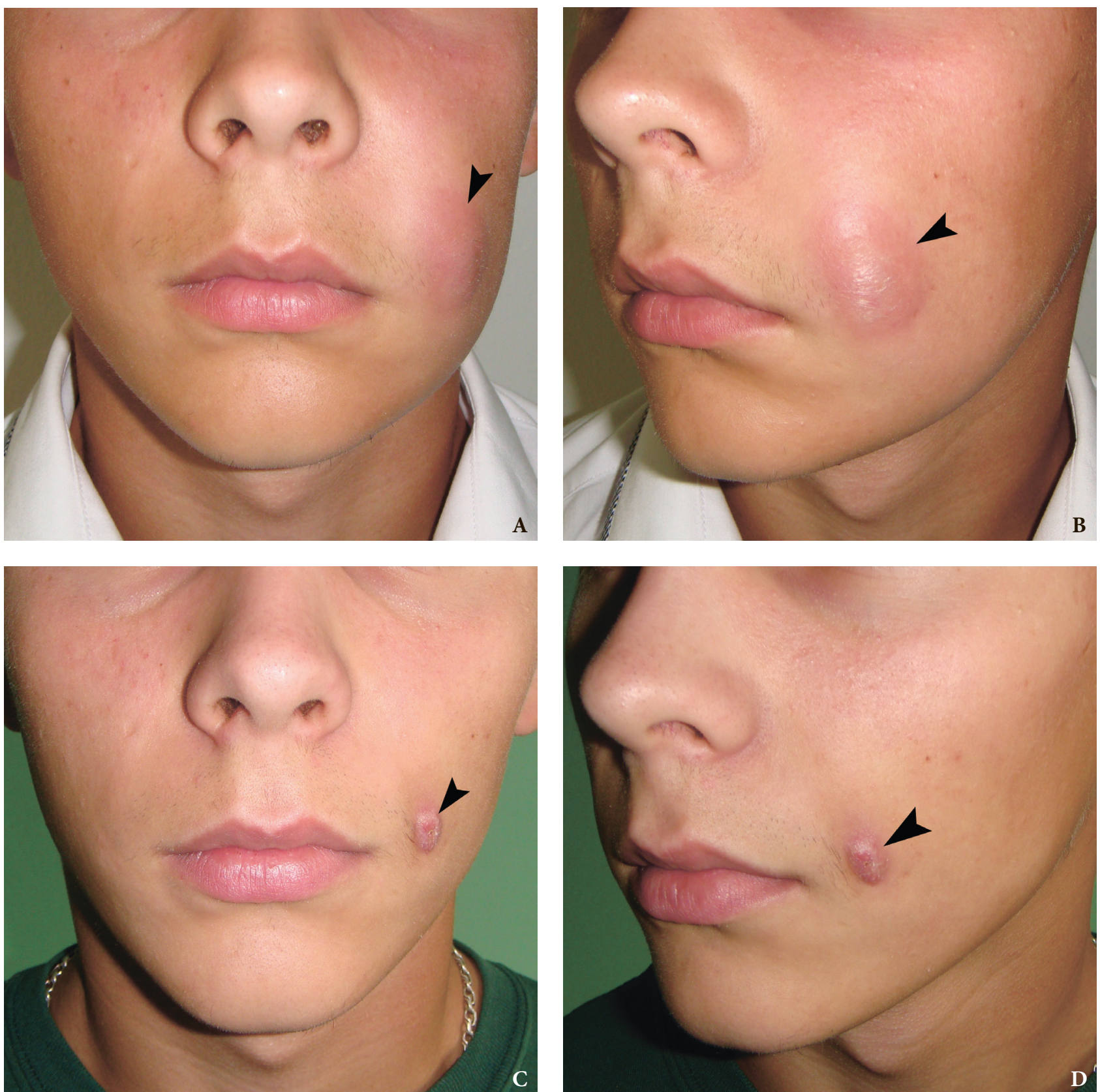

FIGURE 4. Case 4: An 18-year-old male with odontogenic cutaneous sinus tract to left nasolabial fold and cheek from the upper left first molar (ie, tooth \#2.6). Images $\mathbf{A}$ and $\mathbf{B}$ are taken at moment of the developed abscess (arrow). Images $\mathbf{C}$ and $\mathbf{D}$ are taken on day 19 after the subcutaneous abscess have been surgically drained: Noted a nodule in a place of the previously treated abscess. Printed with permission and copyrights retained by I.I.F. (Fig 4 continued on next page.) 

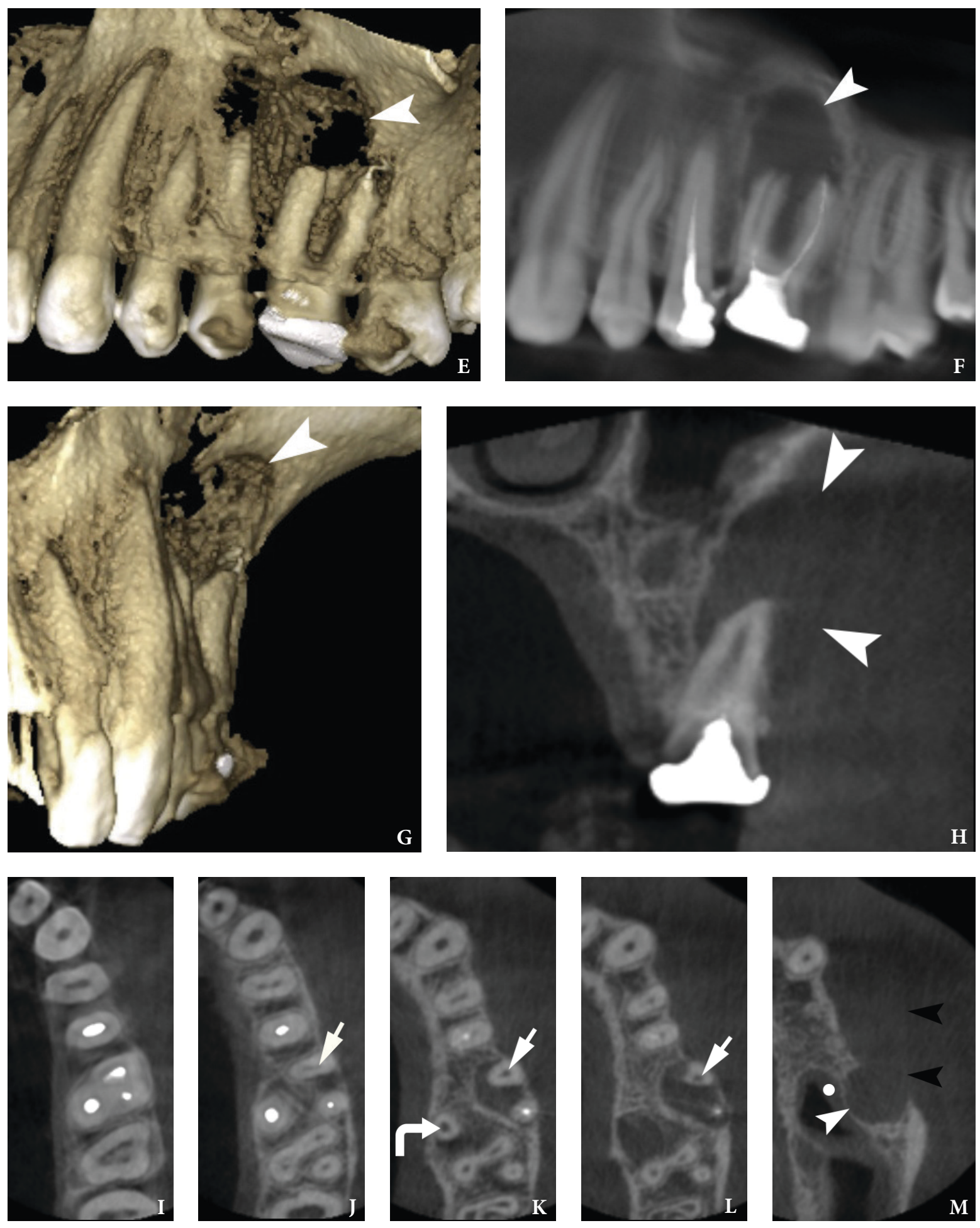

FIGURE 4 (continued). Case 4: An 18-year-old male with odontogenic cutaneous sinus tract to left nasolabial fold and cheek from the upper left first molar (ie, tooth \#2.6). Chronic infection-induced bone defect on 3-dimensional (E, G) and panoramic (obtained using slice autofocus option) (F) CBCT images is indicated by arrowheads. Coronal scan $(\mathbf{H})$ precisely visualizes the alveolar part of the tract (arrowheads). Sequence of axial scans (I- $\mathbf{M})$ showed untreated mesiobuccal canal (arrows) which became a cause of the chronic periapical abscess (white arrowhead). The direction and the lateral wall of the sinus tract are labeled by black arrowheads. Incompletely treated palatal canal is labeled by curved arrow. Larger periapical radiolucency (in the area of buccal roots) (arrowhead) measured $9.17 \times 7.00 \times 13.69 \mathrm{~mm}$. An insignificant (1.72 mm) maxillary sinus mucosa thickening is indicated by dot. Printed with permission and copyrights retained by l.I.F. (Fig 4 continued on next page.) 

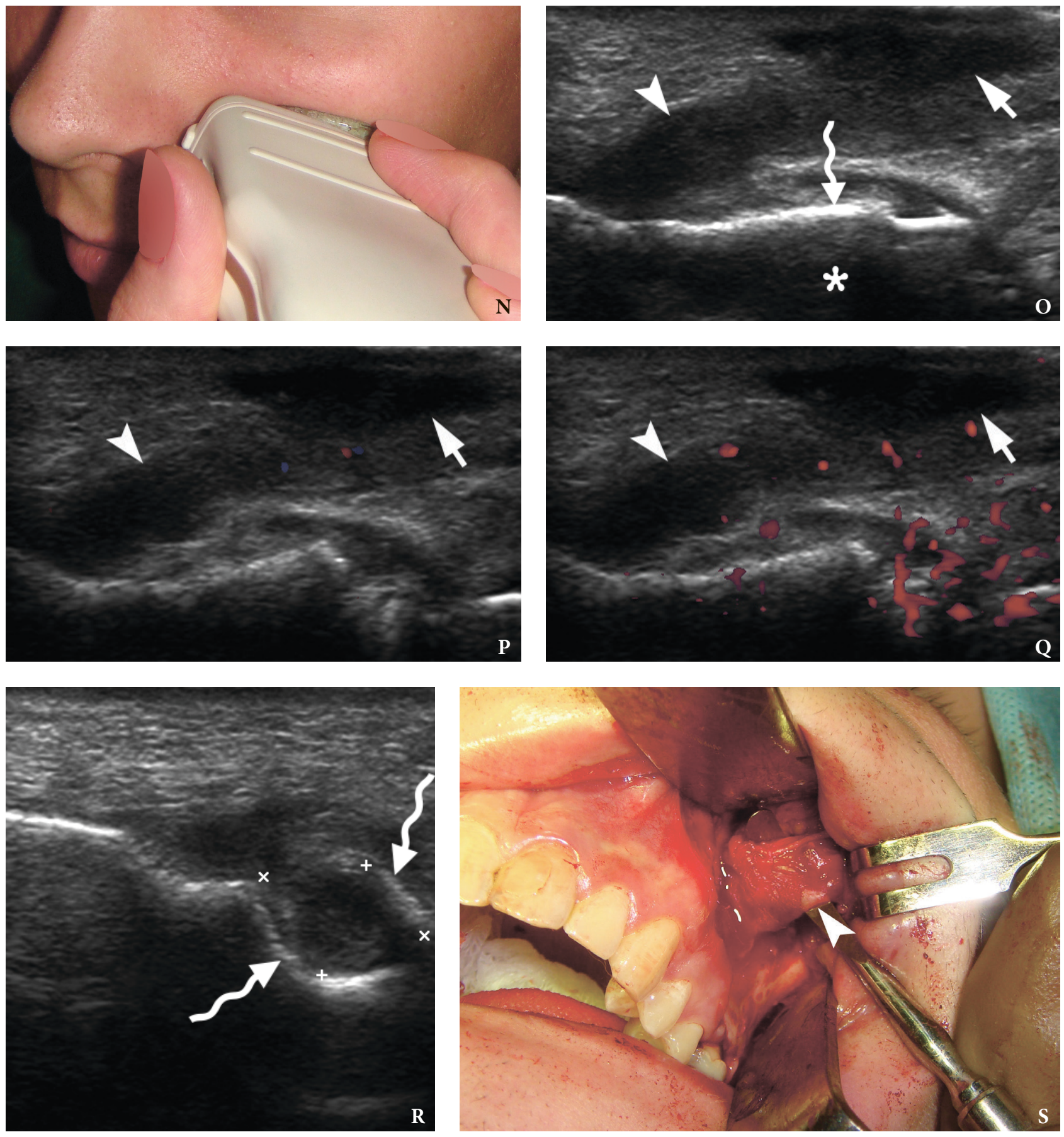

FIGURE 4 (continued). Case 4: An 18-year-old male with odontogenic cutaneous sinus tract to left nasolabial fold and cheek from the upper left first molar (ie, tooth \#2.6). Image $\mathbf{N}$ demonstrates the longitudinal position (related to sinus tract passage) of the linear transducer during ultrasonography (images $\mathbf{0}-\mathbf{Q}$ ) on day 19 after the subcutaneous abscess lancing with antibiotic prescription. Gray scale ultrasound (0) showed hypoechoic triangular well-defined lesion (arrow) (measured $1.11 \mathrm{~cm}$ in longitudinal direction) in subcutaneous layer with a tube-form hypoechoic curved continuation (0.62 $\mathrm{cm}$ in diameter and $2.19 \mathrm{~cm}$ in length) to the echoic surface (waved arrow) of the left maxilla. Artifact of acoustic shadowing is indicated by asterisk. Color (P) and power (Q) Doppler sonograms revealed no intralesional vascularity. This means that there is no acute inflammation in the area of lesion. Gray scale US of the intraosseous part of the tract $(\mathbf{R})$ showed a round shape hypoechoic lesion (indicated by ' + ' and ' $x$ ' calipers) (with heterogenic content) measured $0.7 \times 1.02 \mathrm{~cm}$ and surrounded by echoic borders (waved arrows) of intraosseous maxillary cavity (formed by chronic periapical abscess). At the intraoperative image $\mathbf{( S )}$ the dissected sinus tract (arrowhead) is elevated by an instrument before its excision. Printed with permission and copyrights retained by 0.S.C. (images $\mathbf{0}-\mathbf{R}$ ) and I.I.F (images $\mathbf{S}$ ). 


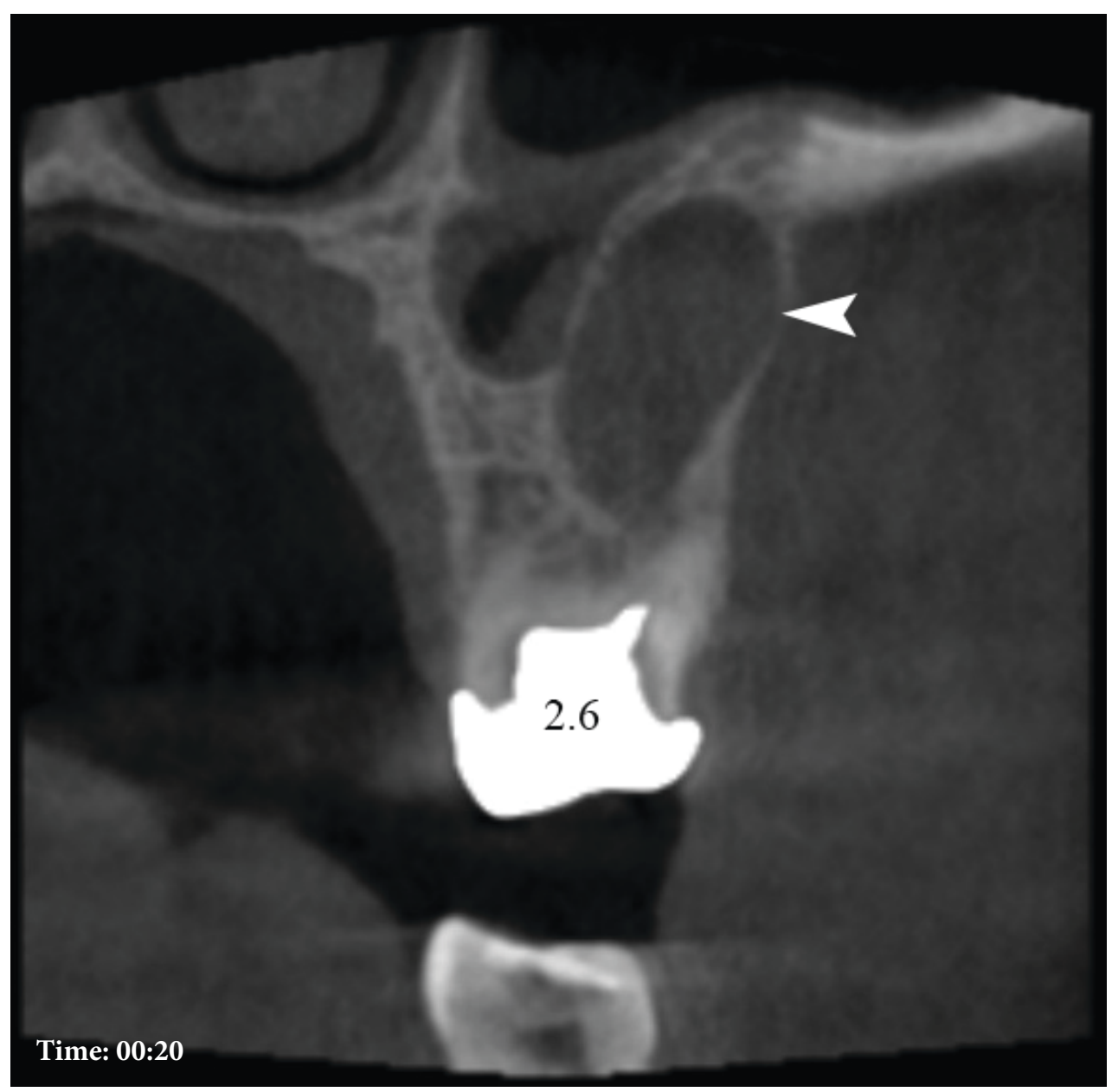

VIDEO 1. Case 4: An 18-year-old male with odontogenic cutaneous sinus tract to left nasolabial fold and cheek from the improperly treated upper left first molar (ie, tooth \#2.6). Video represents a sequence of coronal CBCT scans. Notes two periradicular lesions: 1) a larger one (a sinus tract causative lesion) (arrowhead) around the tooth \#2.6 which involves mesio- and distobuccal root apices and furcation area and 2) a smaller lesion around the apex of the palatal root.

Video is available in the page of the full-text article on dtjournal.org and in the YouTube channel, available at https://youtu.be/QkQDvrRMZYw. Or just point the smartphone/tablet camera at the QR code and click on the pop-up menu "Open ... in ... ." Total video 's duration: 39 seconds.

Printed with permission and copyrights retained by I.I.F.

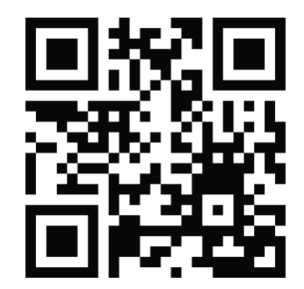

QR code leads to Video 1 at

YouTube channel Videos DTJournal 
TABLE 1. Patient Data, Cutaneous Manifestations of the OCSTs, Associated Teeth, and Management.

\begin{tabular}{|c|c|c|c|c|c|}
\hline Case & $\begin{array}{l}\text { Age }(y r) / \\
\text { Gender }\end{array}$ & Cutaneous Manifestations & $\begin{array}{c}\text { Area of } \\
\text { Manifestations }\end{array}$ & Tooth \# & Management \\
\hline 1 & $24 / \mathrm{M}$ & $\begin{array}{l}\text { Cutaneous infiltration with } \\
\text { formation of the abscess }\end{array}$ & $\begin{array}{l}\text { Left mandibular } \\
\text { body }\end{array}$ & 3.6 & Tooth extraction + antibiotics \\
\hline 2 & $41 / \mathrm{M}$ & Fistula with deep dimpling & $\begin{array}{l}\text { Right mandibular } \\
\text { body }\end{array}$ & 4.7 & $\begin{array}{l}\text { Tooth extraction, tract }+ \text { cutaneous lesion } \\
\text { excision, and local skin plasty }\end{array}$ \\
\hline \multirow[b]{2}{*}{3} & \multirow[b]{2}{*}{$45 / \mathrm{M}$} & Fistula with dimpling & Left cheek & 2.7 & The patient refused any treatment \\
\hline & & $\begin{array}{l}\text { Scar after treated fistula with } \\
\text { dimpling }\end{array}$ & $\begin{array}{l}\text { Left mandibular } \\
\text { body }\end{array}$ & 3.6 & $\begin{array}{l}\text { In anamnesis: tooth extraction, tract }+ \\
\text { cutaneous lesion excision, and local skin } \\
\text { plasty was performed }\end{array}$ \\
\hline \multirow[b]{2}{*}{4} & \multirow[b]{2}{*}{$18 / \mathrm{M}$} & Abscess at first consultation & \multirow[b]{2}{*}{ Left nasolabial fold } & \multirow[b]{2}{*}{2.6} & \multirow{2}{*}{$\begin{array}{l}\text { First visit - abscess lancing, second visit - } \\
\text { tooth extraction and excision of the skin } \\
\text { lesion with a sinus tract }\end{array}$} \\
\hline & & $\begin{array}{l}\text { Nodule at day } 19 \text { after abscess } \\
\text { lancing }\end{array}$ & & & \\
\hline
\end{tabular}

\section{DISCUSSION}

Odontogenic cutaneous sinus tract can be termed as "chronic periapical abscess with an extraoral sinus opening ${ }^{13}$ ". Metzger et al applied a similar term, "a chronic apical abscess," describing the origin of OCST. ${ }^{14}$ Giménez-García et al ${ }^{15}$ highlighted that sinus tracts can also originate from loci of the osteomyelitis, osteonecrosis, suppurative infections, infected cysts, and tubercular infection. Even the case of an extraoral draining actinomycotic sinus tract with bifurcation was described by Göçmen et al.

Kishore Kumar et al's clinical study of 200 patients with cutaneous sinuses of the cervicofacial region clearly showed that 80 percent of them are of odontogenic origin.

Usually OCST appears as a single unilateral pathologic process, but in rare cases can be noted a several OCSTs (ie, multiple OCSTs) ${ }^{5,6}$ what is proved by the case 3 (with unilateral multiple OCSTs) of our report. The multiple OCSTs in the study of Sakamoto and Stratigos were named as bilateral cutaneous sinus tracts of dental etiology due to the localization of the last. ${ }^{1}$

Tremendously huge variety of cutaneous manifestations of the OCSTs leads to its different clinical descriptions in the publications, terms, and the number of initial misdiagnosis ${ }^{19}$.

Lee et $\mathrm{al}^{3}$ in 2016, based on the analysis of thirty-four OCSTs, described four most common morphological types of cutaneous manifestations:

1. Dimpling (41.2 percent).
2. Nodule (32.4 percent).

3. Abscess (20.6 percent).

4. Cyst (5.9 percent).

Literature also allocates such forms of skin lesion appearances of the OCSTs like cutaneous infiltration $^{5,6}$, suppurated nodule, ${ }^{7}$ and even seventh form of manifestations-odontogenic cutaneous granuloma with fistula.

Trying to highlight a wide variety of descriptions of cutaneous part of the OCSTs, here are just a few of them: 1) erythematous, exophytic nodule with a crusted surface and a central stoma ${ }^{13}$,2) puckered appearance on the $\operatorname{skin}^{20}$, 3) an erythematous, crusted nodule measuring about $50 \mathrm{~mm}$ with pus discharge $^{21}$,4) affected skin can be hyperemic or of a normal color, thinned, cyanotic, glossy, forms folds and unevenness $\left.{ }^{5,6}, 5\right)$ reddish abscess $2.5 \mathrm{~cm}$ in diameter $\left.^{22}, 6\right)$ orocutaneous fistula $\left.{ }^{19}, 7\right)$ granuloma (ie, such type of cutaneous manifestation of OCST [not a pyogenic granuloma]) sizes are variable (from 1 to $\left.3-4 \mathrm{~cm})^{5}, 8\right)$ classically, the lesion presented as an erythematous nodule of diameter up to $2 \mathrm{~cm}$ with or without drainage $e^{23}$,9) nodulocystic cutaneous lesion 7,10$)$ cutaneous fistula with hyperpigmented retracted skin $^{24}$, etc.

Though the term "parulis" is sometimes applied ${ }^{2}$ to the skin part of the OCST, predominantly, the "parulis" (ie, gingival abscess) name, is used for the submucosal abscess in the gingival tissues ${ }^{26}$ linked by fistula with a locus of odontogenic infection and can be diagnosed by gutta-percha point (ie, guttapercha cone $\mathrm{e}^{7}$. Neville et $\mathrm{al}^{27}$ described parulis as 
an exophitic, erythematous or yellowish mass of granulation tissue on the gingival/alveolar mucosa.

In our opinion, all cutaneous manifestations of the OCSTs can be divided into the two types (Fig 5):
1. Manifestations above the skin level (cutaneous infiltration, nodule, and abscess).

2. Manifestations below the skin level (ie, dimpling with active/non-active fistula).
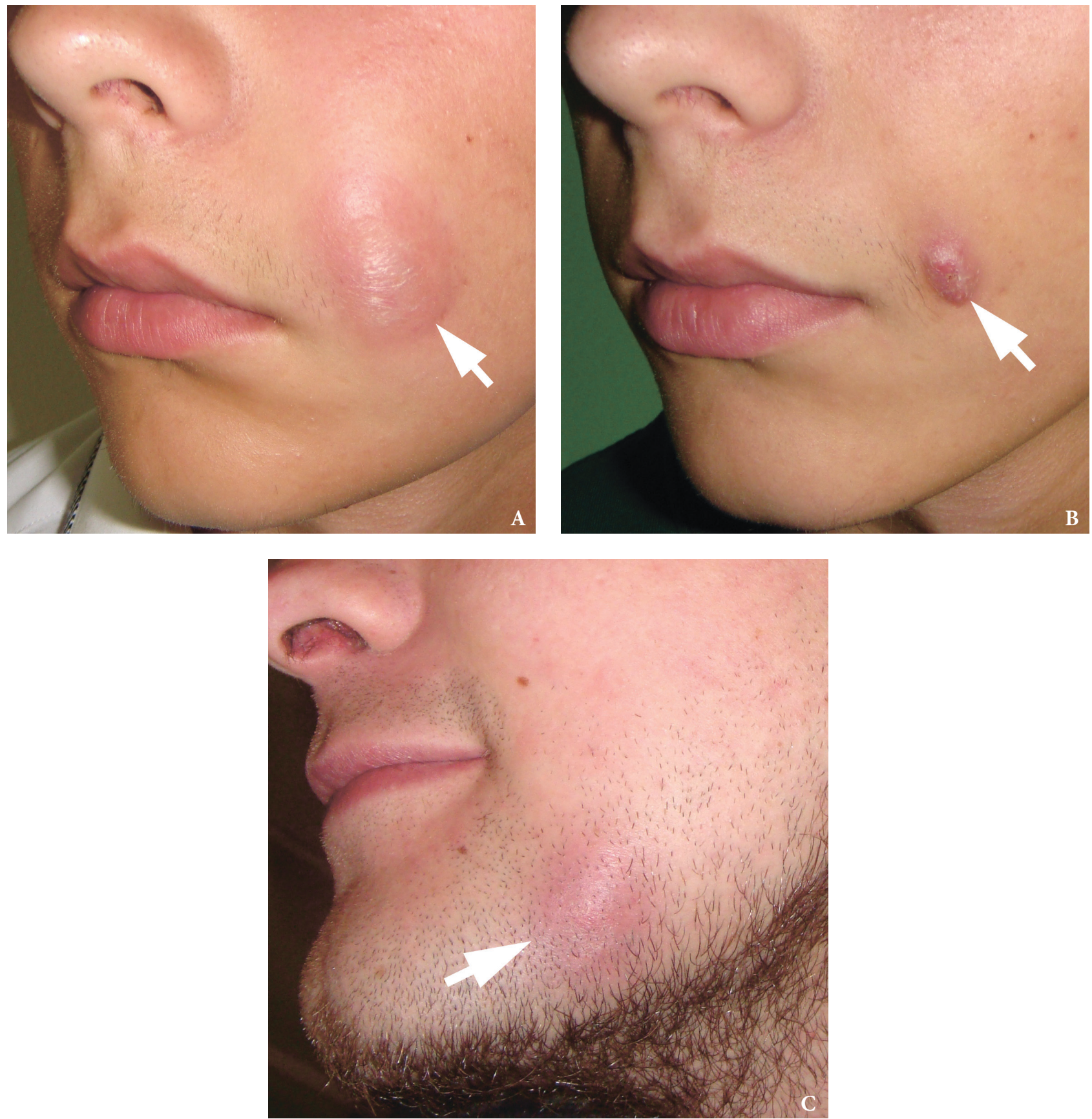

FIGURE 5. Comparison of odontogenic cutaneous sinus tracts with "above" $(\mathbf{A}-\mathbf{C})$ and "below the skin level" (D, E) cutaneous manifestations in four patients. Abscess $(\mathbf{A})$, nodule $(\mathbf{B})$, cutaneous infiltration $(\mathbf{C})$, dimpling with non-active fistula $(\mathbf{D})$, and the deep dimpling with active fistula (E) are labeled by arrows. (Fig 5 continued on next page.) 

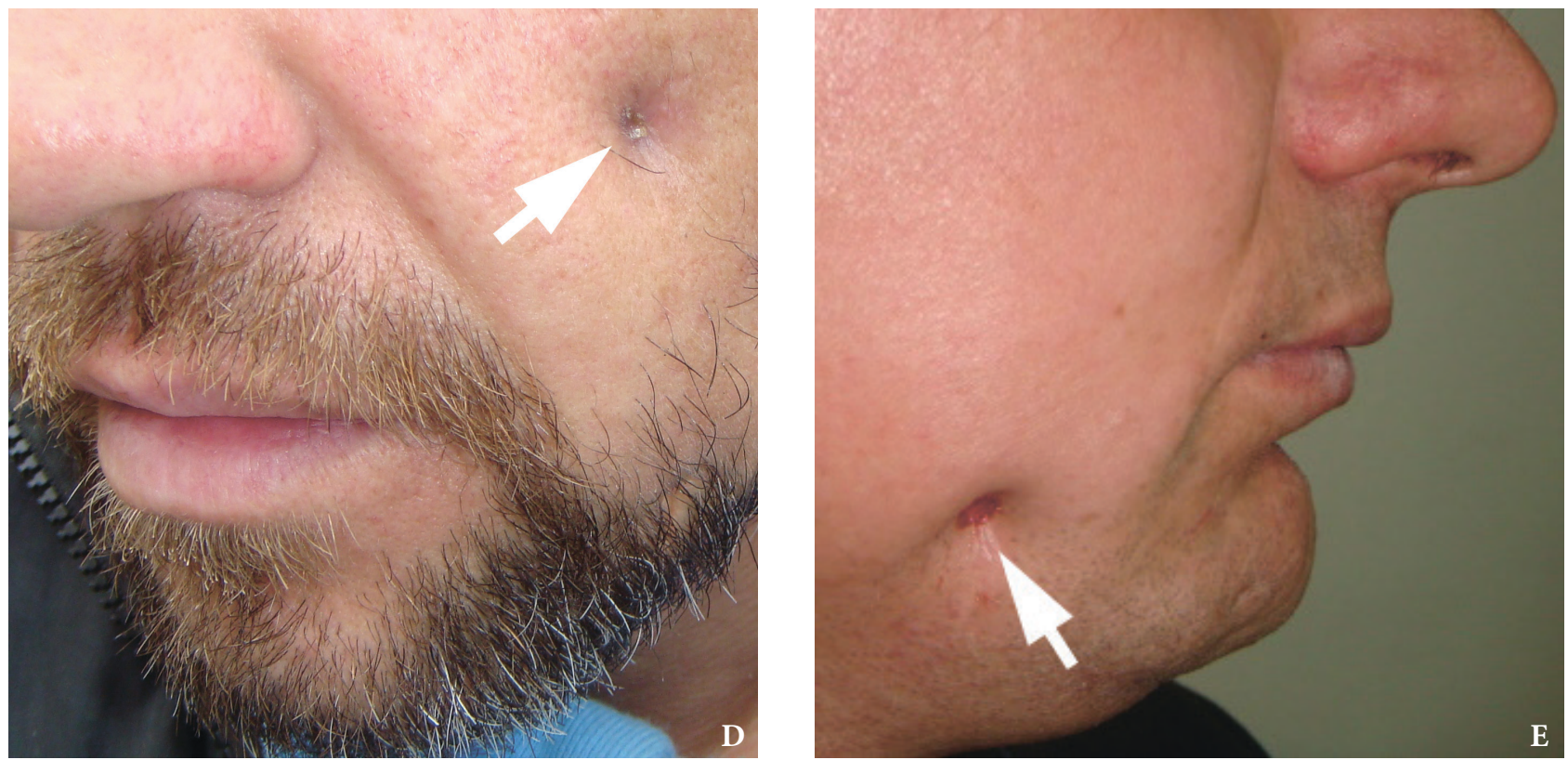

FIGURE 5 (continued). Comparison of odontogenic cutaneous sinus tracts with "above" $(\mathbf{A}-\mathbf{C})$ and "below the skin level" (D, E) cutaneous manifestations in four patients. Abscess $(\mathbf{A})$, nodule $(\mathbf{B})$, cutaneous infiltration $(\mathbf{C})$, dimpling with non-active fistula (D), and the deep dimpling with active fistula (E) are labeled by arrows.

This partitioning of OCST cutaneous part appearances is similar to the partitioning into 1) odontogenic cutaneous fistulas and 2) odontogenic subcutaneous granulomas. ${ }^{5,6}$

It should be remembered that 50 percent of patients affected by OCSTs are subjected to incorrect management before the correct diagnosis is established. ${ }^{28}$ But it's easy to avoid the misdiagnosis by using the combination of such an advanced technologies like ultrasonography (ie, ultrasound [US]) and CBCT. There is an urgent need to highlight for oral and maxillofacial surgeons the advantages of the US for their practice in general and for the diagnostics of the OCSTs in particular.

The differential diagnosis of OCST includes the sinus tracts of all other origins (actinomycosis, osteomyelitis, etc) ${ }^{16,17}$, pyogenic granuloma $^{19}$, non-odontogenic subcutaneous granuloma ${ }^{5,6}$, infected sebaceous gland cyst (also known as atheroma) ${ }^{5}$, suppurative lymphadenitis ${ }^{5,21}$, furuncle ${ }^{29}$, malignancies ${ }^{30,31}$, etc. Moreover, Kim et al reported a unique case of cutaneous basal cell carcinoma arising in the area of odontogenic cutaneous fistula in a 64-year-old male patient.

Pseudofluctuation (feeling upon palpation for the false wavelike motion of the collected fluid [eg, pus]) is one of the core sings for the OCST manifested as a subcutaneous granuloma. ${ }^{6}$ In fact, the symptom of pseudofluctuation is explained by the abundance of granulation tissue in the pathological focus.

Honestly saying, Lee, Oh, and Yoon and other authors ${ }^{27,33}$ are more than right when notice that a term "pyogenic granuloma" is a misnomer as it does not contain purulent content and is not, strictly speaking, a granuloma upon the histopathological examination.

The best way to avoid OCST misdiagnosis and mismanagement is to choose the best diagnostic technology or its combination. Such a radiation free imaging modality as ultrasound proved its efficacy even upon assessment of jaw bone healing after rootend surgeries. ${ }^{34}$ The soft tissues US investigation has even much wider diagnostic horizons. And we found four English language articles which described fifteen OCST cases examined by US (Table 2): 3 (Shobatake et al, 2014) ${ }^{7}, 1$ (Garido Colmenero et al, 2015) ${ }^{10}, 1$ (Lee and Yun, 2016) , and 10 cases (Cotti et al, 2019) $)^{4}$. Two papers (50 percent) were published in dermatological journals, one (25 percent) in the emergency medicine journal, and one (25 percent) in the dental journal devoted to endodontics.

Analyzing the international experience and our case we summarized the US features of the OCSTs in the Table 3.

So, the US proved its usefulness in understanding 
TABLE 2. English Language Publications Which Describe Ultrasonography of the OCSTs.

\begin{tabular}{|c|l|c|c|l|}
\hline$\#$ & \multicolumn{1}{|c|}{ Authors and Article's Title } & Year & $\begin{array}{c}\text { Number of } \\
\text { Examined OCSTs }\end{array}$ & \multicolumn{1}{|c|}{ Journal } \\
\hline 1 & $\begin{array}{l}\text { Shobatake et al. Usefulness of ultrasonography for rapidly diagnosing } \\
\text { cutaneous sinus tracts of dental origin. }\end{array}$ & 2014 & 3 & $\begin{array}{l}\text { European Journal of } \\
\text { Dermatology }\end{array}$ \\
\hline 2 & $\begin{array}{l}\text { Garrido Colmenero et al. Diagnostic value of color Doppler } \\
\text { ultrasound for cutaneous odontogenic sinus tract. }{ }^{10}\end{array}$ & 2015 & 1 & $\begin{array}{l}\text { Actas Dermo- } \\
\text { Sifiliográficas }\end{array}$ \\
\hline 3 & $\begin{array}{l}\text { Lee and Yun. Odontogenic cutaneous sinus tract presenting as a } \\
\text { growing cheek mass in the emergency department. }\end{array}$ & 2017 & 1 & $\begin{array}{l}\text { American Journal of } \\
\text { Emergency Medicine }\end{array}$ \\
\hline 4 & $\begin{array}{l}\text { Cotti et al. Ultrasound examination to visualize and trace sinus tracts } \\
\text { of endodontic origin. }\end{array}$ & 2019 & 10 & Journal of Endodontics \\
\hline
\end{tabular}

TABLE 3. Ultrasound Appearance (Description) of Different Parts of the OCSTs Based on the Data of Literature and Our Report.

\begin{tabular}{|c|c|c|c|}
\hline Article & $\begin{array}{c}\text { Intra- } / \\
\text { Periosseous Part }\end{array}$ & Sinus Tract & $\begin{array}{c}\text { Cutaneous/ } \\
\text { Subcutaneous Part }\end{array}$ \\
\hline Shobatake et $\mathrm{al}^{7}$ & No data & $\begin{array}{l}\text { Gray scale US: Hypoechoic band } \\
\text { that originated from the cutaneous } \\
\text { lesion and extended through the } \\
\text { subcutaneous tissue to the alveolar } \\
\text { bone. } \\
\text { Color Doppler US showed some } \\
\text { color signals around the lesion }\end{array}$ & No data \\
\hline Garrido Colmenero et $\mathrm{al}^{10}$ & No data & $\begin{array}{l}\text { Gray scale US: A slightly tortuous, } \\
\text { relatively well-defined, hypoechoic } \\
\text { linear structure extending to the } \\
\text { surface of the cortical plate of the } \\
\text { jaw }\end{array}$ & No data \\
\hline Lee and Yun ${ }^{1}$ & No data & $\begin{array}{l}\text { Gray scale US: A heterogeneous } \\
\text { hypoechoic mass }\end{array}$ & $\begin{array}{l}\text { Gray scale US: Hyperechoic. } \\
\text { Color Doppler US reveals } \\
\text { intralesional vascularity }\end{array}$ \\
\hline Cotti et $\mathrm{al}^{4}$ & $\begin{array}{l}\text { Gray scale US: Apical } \\
\text { periodontitis visualized as } \\
\text { anechoic to hypoechoic areas }\end{array}$ & $\begin{array}{l}\text { Gray scale US: The sinus tracts } \\
\text { appeared as dishomogeneous, } \\
\text { hypoechoic pathways lined by } \\
\text { echogenic and reinforced walls }\end{array}$ & $\begin{array}{l}\text { Gray scale US: Hypoechoic } \\
\text { band (ie, sinus tract) crossed the } \\
\text { muscular layer of the muscle to } \\
\text { reach the surface of the skin }\end{array}$ \\
\hline $\begin{array}{l}\text { Our study: } \\
\text { Cherniak et al }\end{array}$ & $\begin{array}{l}\text { Gray scale US: Round- } \\
\text { shape hypoechoic lesion } \\
\text { (with heterogenic content) } \\
\text { surrounded by echoic borders } \\
\text { of pathologic intraosseous } \\
\text { jaw cavity }\end{array}$ & $\begin{array}{l}\text { Gray scale US: Tube-form (curved } \\
\text { strand) hypoechoic continuation } \\
(0.62 \mathrm{~cm} \text { in diameter and } 2.19 \mathrm{~cm} \\
\text { in length) of the cutaneous lesion } \\
\text { to the echoic jaw surface }\end{array}$ & $\begin{array}{l}\text { Gray scale US: A hypoechoic } \\
\text { triangular well-defined } \\
\text { lesion (measured } 1.11 \mathrm{~cm} \\
\text { in longitudinal direction) in } \\
\text { subcutaneous layer }\end{array}$ \\
\hline
\end{tabular}


weather the cutaneous lesion has the sinus tract and in helping to trace its direction (ie, to perform ultrasound tracing [synonym: ecographic tracing $\left.{ }^{4}\right]$ ) and find the locus of its origin.

Highest precision of endodontic diagnosis/ management in cases of the OCSTs is proved by the studies highlighted the CBCT. ${ }^{35,36}$ Sodnom-Ish et al presented the arguments for using a CT with soft tissue window setting, as the path of the sinus tract was easily identified in both of their cases. ${ }^{28}$ Figure $4 \mathrm{M}$ also demonstrates the possibilities of CBCT in the identification of the sinus tract.

Swales et al's review analysis of the implemented treatment tactics showed its great variety. ${ }^{29}$ But the most correct choice of treatment in every particular situation will be possible if we take into consideration two core things: 1) microscopical composition of the sinus tracts and 2) all pro and contra of management tactics.

Harrison and Larson proved that 9 of the 10 intraoral (ie, oral) sinus tracts (ie, those which extend from periapical lesions to the alveolar mucosa) were lined with granulation tissue that contained chronic inflammatory cells. ${ }^{37}$ Only one of the 10 was lined with stratified squamous epithelium. ${ }^{37}$ The authors concluded that there is no dependence of presence of the epithelial lining from the existence of the sinus tract. ${ }^{37,38}$

Baumgartner et al presented a study based on 30 examined oral sinus tracts and in 67 percent of cases the sinus tracts were lined by granulomatous tissue and only in 33 percent cases by epithelial lining to the level of periapex..$^{38}$ In the investigated cases the epithelial lining originated not from the periapical lesion's epithelium but from the mucosal surface. ${ }^{37}$

Bai et al presented a data of 53-year-old man with OCST of the submental area from lower left second molar; and pathological analysis clearly confirmed that the tract was lined with granulation tissue. ${ }^{3}$

In a 64-year-old male patient with cutaneous basal cell carcinoma arising in odontogenic cutaneous fistula the sinus tract was also lined by inflamed granulation tissue. ${ }^{32}$

Chang highlighted two case reports (23-year-old and 55-year-old males) with extraoral odontogenic sinus tracts which included its excision and in both patients the histologic report revealed chronic inflammation with fibrosis. ${ }^{40}$

Other sources, which describe an odontogenic subcutaneous granuloma (as an OCST manifestations), reported the presence of granulation tissue in subcutaneous layer (in a place of cutaneous lesion), where it develops in the form of separate clusters - granulomas.,

The sinus tract lining with granulations was also proved by our two cases (case 2 and 4). This pathohistological feature of sinus tracts in the published reports and in our cases supports the opinions presented in the works of Barrowman et $\mathrm{al}^{41}$ and Pasternak-Júnior et $\mathrm{al}^{42}$ that OCSTs can and should be treated endodontically. Berman and Rotstein insisted that presence/absence of an epithelial lining does not seem to prevent closure of the tract as long as the source of the problem is properly diagnosed and adequately treated and the tooth-associated infection has eliminated. ${ }^{2}$

Thus, although conservative treatment ${ }^{22,29,36}$ nowadays is highly advocated, we strongly recommend (taking into account the experience from Korea) $)^{32}$ to choose between two different management combinations for the group of elderly patients: 1) endodontic plus surgical treatment (apicoectomy + excision of the tract and cutaneous lesion) or 2) necrotic tooth extraction + excision of the tract and cutaneous lesion.

But we should remember the experience of Pérez-Alfonzo et $\mathrm{al}^{43}$ who emphasized that OCST can be refractory to standard treatments in cases of possible infection due to nontuberculous mycobacteria.

Varghese et al notice: in some cases (when the cutaneous changes are reversible) endodontic treatment of the necrotic tooth alone can eliminate the need for surgery, and in other cases (when the cutaneous changes are irreversible) - at least such treatment can improve the condition of the tissues in area of cutaneous lesion. ${ }^{13}$ Resolution of dimpling and hyperpigmentation is usually very slow and it can remain for a long time. So, the surgical revision may be needed for esthetic reasons.

Rahpeyma and Khajehahmadi recommended performing a needle subcision for the conservative treatment for facial dimpling after elimination of the source of odontogenic infection. ${ }^{4}$

It's important to understand that possibility of the extraoral sinus tract to develop appears not only in the case of chronic periapical abscess but also in cases after the tooth extraction. ${ }^{45}$ In about 19 percent of the 117 patients (with nonhealing sinuses and fistulous tracts) from the study of Chowdri et al, the 
sinus tracts followed teeth extractions. ${ }^{45}$ Such postextraction sinus tract may be caused by incorrect sterilization, antibiotic use, surgical technique, or attempted tooth extraction in the presence of infection..$^{45}$

Summarizing, it's important to remember the opinion of Jibbe and Tolkachjov. ${ }^{46}$ No matter what is a level of radiological knowledge of the surgeon the need to re-read or to re-watch the sonograms or CT scans are very important when clinical suspicion does not correlate with the radiological report. ${ }^{46}$ Also, taking into consideration the histological structure of the extraoral sinus tract itself and its skin manifestations, we can consider appropriate to continue to use the term odontogenic subcutaneous granuloma in a certain cases, but with mandatory indication of its clinical stage. Such cases are above the skin level manifestations of the OCST like cutaneous infiltration, nodule, and abscess.

\section{CONCLUSIONS}

In sum, the odontogenic cutaneous sinus tract is a collective term for the locus of toothassociated infection and pathologic exudatedraining tube-shape formation to one of at least seven possible cutaneous manifestations, such as dimpling with fistula, cutaneous infiltration, abscess, nodule, suppurated nodule, odontogenic cutaneous granuloma with fistula, or even cyst-like lesion. Moreover, those manifestations can transform one into another depending on different reasons, what is proved by a literature and our cases. Combination of diagnostics methods like ultrasound and computed tomography can guarantee the highest level of accuracy in establishing the diagnosis and lowest level of mistreatment especially for the less experienced doctors.

\section{TERM OF CONSENT}

Written patient consent was obtained from all patients to publish the clinical photographs.

\section{AUTHOR CONTRIBUTIONS}

Conceptualization: Fesenko II. Data acquisition: Cherniak OS, Snisarevskyi PP, Zaritska VI, Pavlenko RA. Data analysis or interpretation: Koba NM, Fesenko II. Drafting of the manuscript: Blinova VP,
Holodenko VM. Critical revision of the manuscript: Zaritska VI, Fesenko II, Cherniak OS. Approval of the final version of the manuscript: all authors.

\section{CONFLICT OF INTERESTS}

The authors declare no conflict of interest.

\section{FUNDINGS}

No funding was received for this study.

\section{REFERENCES}

1. Lee SH, Yun SJ. Odontogenic cutaneous sinus tract presenting as a growing cheek mass in the emergency department. Am J Emerg Med 2017;35(5):808.e5-808. e7. https://doi.org/10.1016/j.ajem.2016.12.024

2. Guevara-Gutiérrez E, Riera-Leal L, Gómez-Martínez M, Amezcua-Rosas G, Chávez-Vaca CL, TlacuiloParra A. Odontogenic cutaneous fistulas: clinical and epidemiologic characteristics of 75 cases. Int J Dermatol 2015;54(1):50-5. https://doi.org/10.1111/ijd.12262

3. Lee EY, Kang JY, Kim KW, Choi KH, Yoon TY, Lee JY. Clinical characteristics of odontogenic cutaneous fistulas. Ann Dermatol 2016;28(4):417-21. https:// doi.org/10.5021/ad.2016.28.4.417

4. CottiE, Musu D, Goddi A, DettoriC,Campisi G, Shemesh $\mathrm{H}$. Ultrasound examination to visualize and trace sinus tracts of endodontic origin. J Endod 2019;45(10):118491. https://doi.org/10.1016/j.joen.2019.07.009

5. Tymofieiev OO. Manual of maxillofacial and oral surgery [Russian]. 5th ed. Kyiv, Ukraine: Chervona Ruta-Turs; 2012.

6. Tymofieiev OO. Maxillofacial surgery and surgical dentistry [Russian]. Kyiv, Ukraine: Medicine; 2020.

7. Shobatake C, Miyagawa F, Fukumoto T, Hirai T, Kobayashi N, Asada H. Usefulness of ultrasonography for rapidly diagnosing cutaneous sinus tracts of dental origin. Eur J Dermatol 2014; 24(6):683-7. https://doi. org/10.1684/ejd.2014.2441

8. Tidwell E, Jenkins JD, Ellis CD, Hutson B, Cederberg RA. Cutaneous odontogenic sinus tract to the chin: a case report. Int Endod J 1997;30(5):352-5. https://doi. org/10.1046/j.1365-2591.1997.00084.x

9. Jacobs HG. Contribution to clinical findings of the so-called chronic granulating periodontitis Partsch. Dtsch Stomatol 1991;41(6):214-8.

10. Garrido Colmenero C, Blasco Morente G, Latorre Fuentes JM, Ruiz Villaverde R. Diagnostic value of color Doppler ultrasound for cutaneous odontogenic sinus tract [English,Spanish]. Actas Dermosifiliogr 2015;106(8):67880. https://doi.org/10.1016/j.ad.2014.12.023 
11. Block MS, Dastoury K. Prevalence of sinus membrane thickening and association with unhealthy teeth: a retrospective review of 831 consecutive patients with 1,662 cone-beam scans. J Oral Maxillofac Surg 2014;72(12):2454-60. https://doi.org/10.1016/j. joms.2014.06.442

12. Bornstein MM, Wasmer J, Sendi P, Janner SF, Buser D, von Arx T. Characteristics and dimensions of the Schneiderian membrane and apical bone in maxillary molars referred for apical surgery: a comparative radiographic analysis using limited cone beam computed tomography. J Endod 2012;38(1):51-7. https://doi.org/10.1016/j.joen.2011.09.023

13. Varghese LL, Bhattacharya A, Sharma P, Apratim A. Non-surgical management of an extraoral cutaneous sinus tract of odontogenic origin. BMJ Case Rep 2020;13(7):e234699. https://doi.org/10.1136/bcr-2020234699

14. Metzger Z, Abramovitz I, Bergenholtz G. Apical periodontitis. In: Bergenholtz G, Hørsted-Bindslev P, Reit C, editors. Textbook of endodontology. 2nd ed. Wiley-Blackwell: Oxford, United Kingdom; 2010:113-27.

15. Giménez-García R, Martinez-Vera F, Fuentes-Vera L. Cutaneous sinus tracts of odontogenic origin: two case reports. J Am Board Fam Med 2015;28(6):83840. https://doi.org/10.3122/jabfm.2015.06.150046

16. Göçmen G, Varol A, Göker K, Basa S. Actinomycosis: report of a case with a persistent extraoral sinus tract. Oral Surg Oral Med Oral Pathol Oral Radiol Endod 2011;112(6):e121-3. https://doi.org/10.1016/j. tripleo.2011.06.008

17. Kishore Kumar RV, Devireddy SK, Gali RS, Chaithanyaa N, Chakravarthy C, Kumarvelu C. Cutaneous sinuses of cervicofacial region: a clinical study of 200 cases. J Maxillofac Oral Surg 2012;11(4):411-5. https://doi. org/10.1007/s12663-012-0353-y

18. Sakamoto E, Stratigos GT. Bilateral cutaneous sinus tracts of dental etiology: report of case. J Oral Surg 1973;31(9):701-4.

19. Lee JH, Oh JW, Yoon SH. Orocutaneous fistulas of odontogenic origin presenting as a recurrent pyogenic granuloma. Arch Craniofac Surg 2019;20(1):51-4. https://doi.org/10.7181/acfs.2018.01991

20. Fragiskos FD. Odontogenic infections. In: Fragiskos FD, editor. Oral surgery. 1st ed. Heidelberg, Germany: Springer; 2007: 205-41.

21. Ohta K, Yoshimura H. Odontogenic cutaneous fistula of the face. CMAJ 2019;191(46):E1281. https://doi. org/10.1503/cmaj.190674

22. Chen K, Liang Y, Xiong H. Diagnosis and treatment of odontogenic cutaneous sinus tracts in an 11-year-oldboy: a case report. Medicine (Baltimore) 2016;95(20):e3662. https://doi.org/10.1097/MD.0000000000003662

23. Samir N, Al-Mahrezi A, Al-Sudairy S. Odontogenic cutaneous fistula: report of two cases. Sultan Qaboos Univ Med J 2011;11(1):115-8.

24. Figaro N, Juman S. Odontogenic cutaneous fistula: a cause of persistent cervical discharge. Case Rep Med 2018;2018:3710857. https://doi. org/10.1155/2018/3710857

25. Berman LH, Rotstein I. Diagnosis. In: Berman LH, Hargreaves KM, editors. Cohen's pathways of the pulp expert consult.11th ed. St. Louis, MO, United States: Mosby; 2015:2-32.

26. Eversole LR. Intraoral soft tissues swellings. In: Eversole LR, editor. Clinical outline of oral pathology. 3rd ed. Hamilton, Canada: BC Decker; 2002:111-60.

27. Neville BW, Damm DD, Allen CM, Chi AC. Pulp and periapical disease. In: Neville BW, Damm DD, Allen CM, Chi AC. Color atlas of oral and maxillofacial diseases. Philadelphia, PA, United States: Elsevier; 2019:79-92.

28. Sodnom-Ish B, Eo MY, Kim SM. An accurate diagnosis of odontogenic cutaneous sinus tract by different CT unit setting. J Korean Assoc Oral Maxillofac Surg 2020;46 [article in press].

29. Swales KL, Rudralingam M, Gandhi S. Extraoral cutaneous sinus tracts of dental origin in the paediatric patient. A report of three cases and a review of the literature. Int J Paediatr Dent 2016;26(5):391-400. https://doi.org/10.1111/ipd.12205

30. Baba A, Okuyama Y, Shibui T, Ojiri H. Odontogenic cutaneous fistula mimicking malignancy. Clin Case Rep 2017;5(5):723-4. https://doi.org/10.1002/ccr3.907

31. Okorocha N, Denny JWL, Ardehali B. A dental sinus mimicking skin cancer. BMJ 2018;363:k4461 https:// doi.org/10.1136/bmj.k4461

32. Kim NG, Kim JO, Park YJ, Kim JS, Lee YJ, Lee KS. Cutaneous basal cell carcinoma arising in odontogenic cutaneous fistula. Arch Craniofac Surg 2017;18(2):1414. https://doi.org/10.7181/acfs.2017.18.2.141

33. Patil K, Mahima VG, Lahari K. Extragingival pyogenic granuloma. Indian J Dent Res 2006;17(4):199-202. https://doi.org/10.4103/0970-9290.29864

34. Curvers F, Meschi N, Vanhoenacker A, Strijbos O, Van Mierlo M, Lambrechts P. Ultrasound assessment of bone healing after root-end surgery: echoes back to patient's safety. J Endod 2018;44(1):32-7. https://doi. org/10.1016/j.joen.2017.08.028

35. Shemesh A, Hadad A, Azizi H, Lvovsky A, Ben Itzhak J, Solomonov M. Cone-beam computed tomography as a noninvasive assistance tool for oral cutaneous sinus tract diagnosis: a case series. J Endod 2019;45(7):9506. https://doi.org/10.1016/j.joen.2019.03.017

36. Tian J, Liang G, Qi W, Jiang H. Odontogenic cutaneous sinus tract associated with a mandibular second molar having a rare distolingual root: a case report. Head Face Med 2015;11:13. https://doi.org/10.1186/ 


\section{s13005-015-0072-y}

37. Harrison JW, Larson WJ. The epithelized oral sinus tract. Oral Surg Oral Med Oral Pathol 1976;42(4):5117. https://doi.org/10.1016/0030-4220(76)90299-1

38. Baumgartner JC, Picket AB, Muller JT. Microscopic examination of oral sinus tracts and their associated periapical lesions. J Endod 1984;10(4):146-52. https:// doi.org/10.1016/S0099-2399(84)80117-X

39. Bai J, Ji AP, Huang MW. Submental cutaneous sinus tract of mandibular second molar origin. Int Endod $J$ 2014;47(12):1185-91. https://doi.org/10.1111/iej.12266

40. Chang LS. Common pitfall of plastic surgeon for diagnosing cutaneous odontogenic sinus. Arch Craniofac Surg 2018;19(4):291-5. https://doi. org/10.7181/acfs.2018.02110

41. Barrowman RA, Rahimi M, Evans MD, Chandu A, Parashos P. Cutaneous sinus tracts of dental origin. Med J Aust 2007;186(5):264-5. https://doi. org/10.5694/j.1326-5377.2007.tb00886.x

42. Pasternak-Júnior B, Teixeira CS, Silva-Sousa YT, Sousa-Neto MD. Diagnosis and treatment of odontogenic cutaneous sinus tracts of endodontic origin: three case studies. Int Endod J 2009;42(3):271-
6. https://doi.org/10.1111/j.1365-2591.2008.01519.x

43. Pérez-Alfonzo R, Poleo Brito LE, Vergara MS, Ruiz Damasco A, Meneses Rodríguez PL, Kannee Quintero CE, Carrera Martinez C, Rivera-Oliver IA, Da Mata Jardin OJ, Rodríguez-Castillo BA, de Waard JH. Odontogenic cutaneous sinus tracts due to infection with nontuberculous mycobacteria: a report of three cases. BMC Infect Dis 2020;20(1):295. https:// doi.org/10.1186/s12879-020-05015-5

44. Rahpeyma A, Khajehahmadi S. Needle subcision: a conservative treatment for facial dimpling after elimination of odontogenic infection source: a technical note. Oral Maxillofac Surg 2014;18(4):4158. https://doi.org/10.1007/s10006-013-0429-y

45. Chowdri NA, Sheikh S, Gagloo MA, Parray FQ, Sheikh MA, Khan FA. Clinicopathological profile and surgical results of nonhealing sinuses and fistulous tracts of the head and neck region. J Oral Maxillofac Surg 2009;67(11):2332-6. https://doi.org/10.1016/j. joms.2008.06.084

46. Jibbe A, Tolkachjov SN. Cutaneous odontogenic sinus: an inflammatory mimicker of squamous cell carcinoma and epidermal cysts. Cutis 2020;106(4):196-8. https:// doi.org/10.12788/cutis.0081 